\title{
Modulation of muscle contraction by a cell-permeable peptide
}

\author{
Gisela Tünnemann • Peter Karczewski • \\ Hannelore Haase • M. Cristina Cardoso • Ingo Morano
}

Received: 31 March 2007 /Revised: 18 May 2007 / Accepted: 13 June 2007 / Published online: 24 August 2007

(C) Springer-Verlag 2007

\begin{abstract}
In contrast to immortal cell lines, primary cells are hardly susceptible to intracellular delivery methods such as transfection. In this study, we evaluated the direct delivery of several cell-permeable peptides under noninvasive conditions into living primary adult rat cardiomyocytes. We specifically monitored the functional effects of a cellpermeable peptide containing the 15 amino acid $\mathrm{N}$-terminal peptide from human ventricular light chain-1 (VLC-1) on contraction and intracellular $\mathrm{Ca}^{2+}$ signals after electrical stimulation in primary adult cardiomyocytes. The transducible VLC-1 variant was taken up by cardiomyocytes within 5 min with more than $95 \%$ efficiency and localized to sarcomeric structures. Analysis of the functional effects of the cell-permeable VLC-1 revealed an enhancement of the intrinsic contractility of cardiomyocytes without affecting the intracellular $\mathrm{Ca}^{2+}$. Therefore, peptide transduction mediated by cell-penetrating peptides represents not only a unique strategy to enhance heart muscle function with no secondary effect on intracellular $\mathrm{Ca}^{2+}$ but also an invaluable tool for the modulation and manipulation of protein interactions in general and in primary cells.
\end{abstract}

Keywords Ventricular light chain-1 (VLC-1) .

Cell penetrating peptide (CPP) · Peptide transduction .

Cardiomyocytes $\cdot$ Drug delivery

M. Cristina Cardoso and Ingo Morano contributed equally.

G. Tünnemann · P. Karczewski $\cdot$ H. Haase $\cdot$ M. C. Cardoso $(\bowtie) \cdot$

I. Morano $(\square)$

Max Delbrück Center for Molecular Medicine,

Robert Rössle Str. 10,

13125 Berlin, Germany

e-mail: cardoso@mdc-berlin.de

e-mail: imorano@mdc-berlin.de

\section{Morano}

Charité Medical School, Johannes Müller Institute for Physiology,

Tucholskystr. 2,

10117 Berlin, Germany

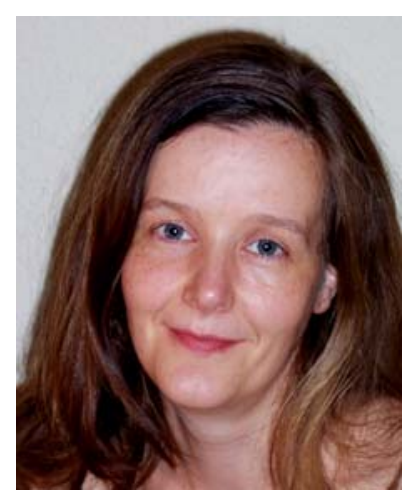

Gisela TÜNNEMANN studied chemistry at the Carl von Ossietzky-University in Oldenburg, Germany. She is presently working in the research group "Molecular and Cell Biology of the (Epi) genome" at the

Max-Delbrück-Center for Molecular Medicine in Berlin, Germany. Her research interests include peptide delivery into living cells, mechanistical aspects of the translocation event of cell-penetrating peptides, and cell cycle regulation.

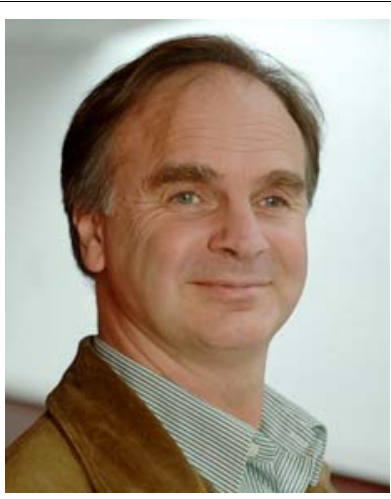

InGO MORANO received his Ph.D. in human sciences and postdoctoral Habilitation in Human Physiology from the Medical Faculty of the University of Heidelberg. He is presently Professor for Molecular Clinical Physiology at the Medical Faculty of the Humboldt University (Charité), Berlin, and leader of the "Molecular Muscle Physiology Group" at the Max-DelbrückCenter, Berlin. His research interests include expression, regulation, and function of contractile handling proteins in smooth and cardiac muscle.

\section{Introduction}

Therapeutical delivery of protein or peptides into living primary cells is hampered by the lack of a suitable and efficient method for the introduction of macromolecules. Most commonly used transfections methods work in immortalized cells but mostly fail in primary cells or require specialized and time-consuming protocols, i.e., production 
of viral vectors. Moreover, the limited life span of primary cells often does not provide sufficient time for expression of gene products and subsequent analysis of their effects. Physical methods such as microinjection and bead loading are highly invasive procedures and are not tolerated by several cell types. It has been known for quite some time that basic proteins like histones or poly-ornithine as well as stretches of basic amino acids within proteins aid the uptake of proteins into mammalian cells $[14,17,20,30]$. In the 1990s, transducible peptides like penetratin- 1 from the homeodomain of Antennapedia [11] and amino acids 48-57 from the transactivator of transcription of human immunodeficiency virus (HIV)-1 [14] were identified and exploited to introduce drugs or biological macromolecules into mammalian cells. Together with other native and synthetic transducing peptides, they are referred to as cell-penetrating peptides (CPPs) [12]. However, it became evident that the invasive methods used to analyze the transduction mediated by CPPs or effects of interconnected cargoes had led to overestimated transduction results and overrated effects of cargoes fused to CPPs [27]. Nevertheless, CPPs mediate the introduction of fused cargoes into living cells, with cargo-dependent mechanistical differences. One uptake mechanism can be described as a slow adsorptive endocytosis and is preferentially used by globular proteins, whereas small compounds like peptides linked to CPPs favor a rapid membrane potential-dependent uptake with overall intracellular availability of the transduced species [33]. CPP-mediated peptide transduction has recently been used to deliver cardioprotective peptides derived from protein kinase $C[4,7-9,24]$, the antiapoptotic BH4 peptide derived from the apoptosis regulator protein $\mathrm{Bcl}-\mathrm{xL}[26,28]$ and a Nox2-derived peptide [34] into isolated cardiomyocytes or whole hearts. We have tested the feasibility of this approach to study muscle function in living adult primary cardiomyocytes. Therefore, we targeted the interaction between actin and the essential myosin light chain (MLC-1) of cardiac type II myosin by a peptide competition approach. Transgenic overexpression of the $\mathrm{N}$ terminus of the human ventricular MLC-1 (residues 1-15; hereafter termed VLC-1), which binds to actin and targets actin/MLC-1 interaction, significantly increased the magnitude and kinetics of the contraction of isolated perfused hearts [21]. We fused the same human VLC-1 peptide to the TAT CPP (VLC-1-TAT) and investigated its uptake, intracellular distribution, and functional consequences in primary living adult rat cardiomyocytes.

\section{Materials and methods}

Isolation of adult rat cardiomyocytes Primary cultures of cardiomyocytes from male WKY rats aged 3 months were performed as described previously [1].
Peptides The peptides consisted of either L-amino acids (capital letters) or of D-amino acids (lower case letters). In case of D-amino acid peptides, functional motifs were synthesized as retro-all D-variants (underlined) to maintain their functionality. Peptides were either labeled with the fluorophore 5,6-carboxy-tetramethylrhodamine (TAMRA) or fluorescein isothiocyanate (FITC). TAT (TAMRA- or FITC-rrrqrrkkrg), $\mathrm{PTD}_{4}[23,33]$ (TAMRA-araqraaaray), and TAT-p21 (TAMRA-rrrqrrkkrgaaAGRKRRQTSMT DFYHSKRRLIFSa-amide) [33] were labeled directly at their $\mathrm{N}$ termini with the indicated fluorophores (Peptide Speciality Laboratories, Heidelberg). In the case of VLC-1 (MAPKKPEPKKSSAKA-C-TAMRA-ME-amide) and VLC-1-TAT (MAPKKPEPKDDAKAPAGRKKRRQRRRC-TAMRA-ME-amide; Biosyntan, Berlin) the TAMRA fluorophore was coupled via an additional cysteine at the $\mathrm{C}$ terminus leaving the $\mathrm{N}$ terminus free for the interaction with actin.

Uptake of transducible peptides and controls To analyze the transduction ability of different compounds into living adult ventricular cardiomyocytes, the primary cells were plated into a laminin-coated $\mu$-slide eight-well ibiTreat (ibidi, Martinsried) or four-well labtek (Nunc, Wiesbaden) microscopy observation chamber. The respective peptides and controls were added directly to Hank's balanced salts solution buffered with $10 \mathrm{mM}$ 4-(2-hydroxyethyl)1-piperazineethanesulfonic acid at $\mathrm{pH} 7.4$ (HBSS) or medium and gently shaken to yield a final concentration of $10 \mu \mathrm{M}$ in case of the peptides and 5,6-TAMRAfluorophore. Trypan blue (Sigma-Aldrich) was added to a final concentration of $0.5 \%(\mathrm{v} / \mathrm{v})$ to the HBSS buffer. For the experiments summarized in Fig. 1 confocal images were acquired $1 \mathrm{~h}$ after addition of the respective compounds to living cardiomyocytes. To study the intracellular localization of transducible peptides in Fig. 3, after 15 min of peptide incubation, the medium was removed, and the cells were washed twice with the HBSS buffer. For subsequent confocal image collection, the cells were kept in medium or buffer. To study the effect of the peptide on muscle contraction and intracellular $\mathrm{Ca}^{2+}$ (Fig. 4), cardiomyocytes were electrically stimulated (see below) to permit the access of the peptides to all actin molecules with potential binding sites. During confocal image collection, the electric stimulation was temporarily switched off.

Microscopy, image acquisition, and analysis Confocal images were acquired with a Zeiss laser scanning microscope LSM510 Meta mounted on an Axiovert 200M inverted microscope using a $63 \times$ phase-contrast oil immersion plan-apochromat objective NA1.4 or a $100 \times$ phasecontrast oil immersion plan-neofluar objective NA1.3. For 
Fig. 1 Peptide uptake and intracellular distribution in living adult cardiomyocytes. To study the uptake capacity of different compounds into primary rat cardiomyocytes, different fluorescent compounds were directly added for $1 \mathrm{~h}$ to the medium or buffer of freshly isolated cardiomyocytes. After the incubation period, confocal images of the cells were taken without exchange of the medium and after removal of the fluorescent solution and exchange against the fresh medium. Internalization into healthy adult cardiomyocytes occurred after application of $10 \mu \mathrm{M}$ of the transducible peptides FITC-TAT shown at low (a) and high magnification (b) and TAMRATAT-p21 shown at low (c) and high magnification (d) but not with application of $10 \mu \mathrm{M}$ of a basic control peptide $\mathrm{PTD}_{4}(\mathbf{e})$. Moreover, $0.5 \%$ of the vital dye trypan blue (f) or $10 \mu \mathrm{M}$ of the TAMRA-fluorophore (g) itself were not able to enter healthy cardiomyocytes (rod-shaped cells in culture). Scale bar, $10 \mu \mathrm{m}$. Stars indicate the nuclei and arrowheads the nucleoli $(N)$ in the higher magnification images. $P C$ Phase contrast, $N P$ nucleoplasm without medium exchange

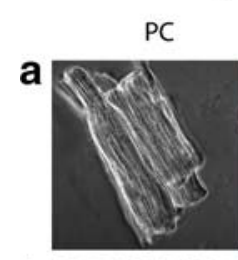

Fluorescence
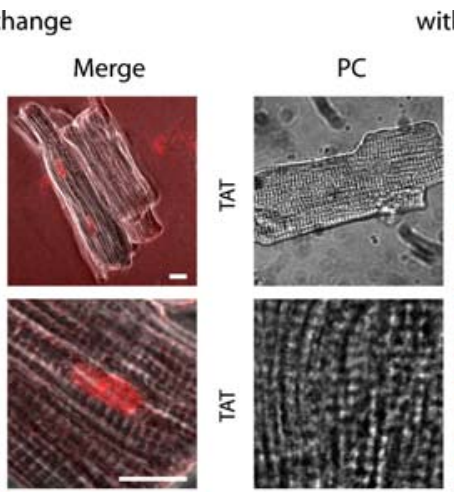

with medium exchange
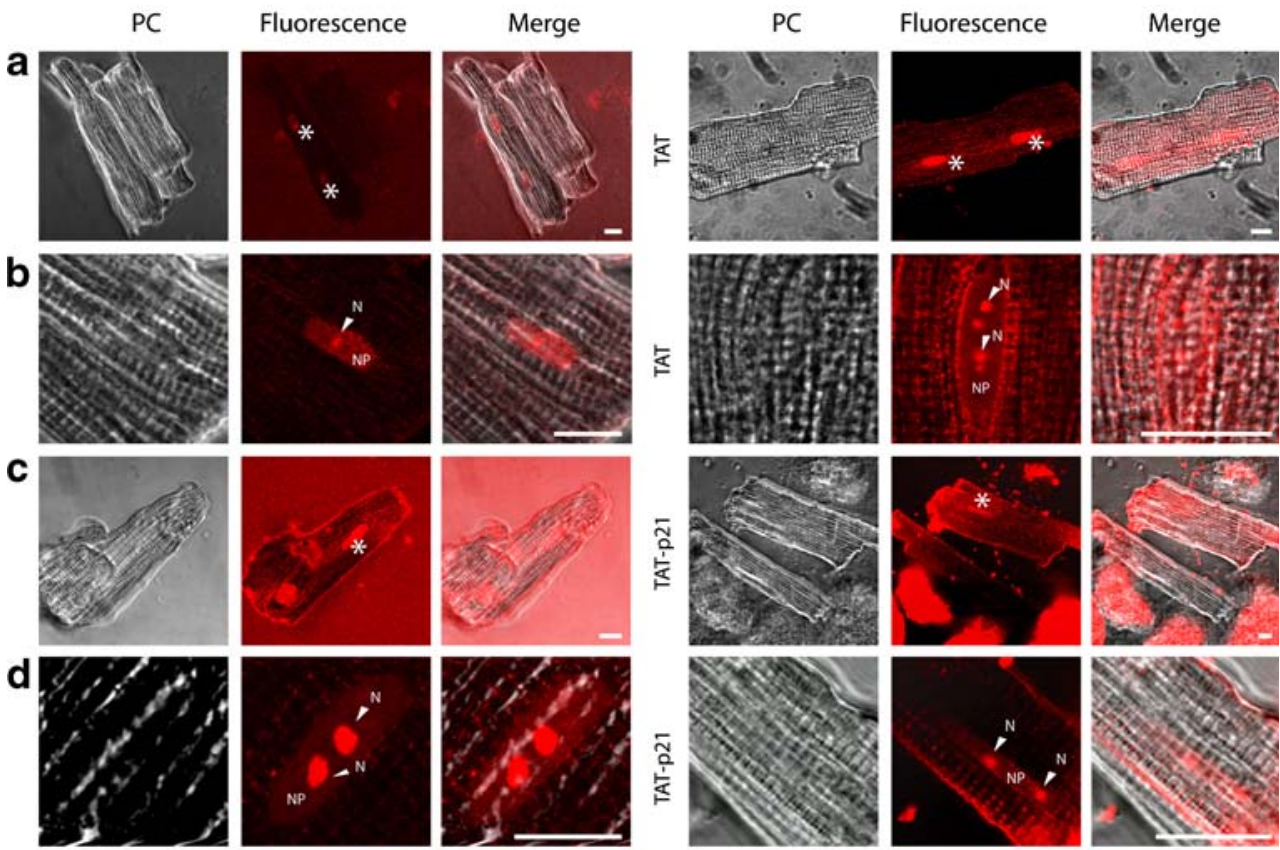

e
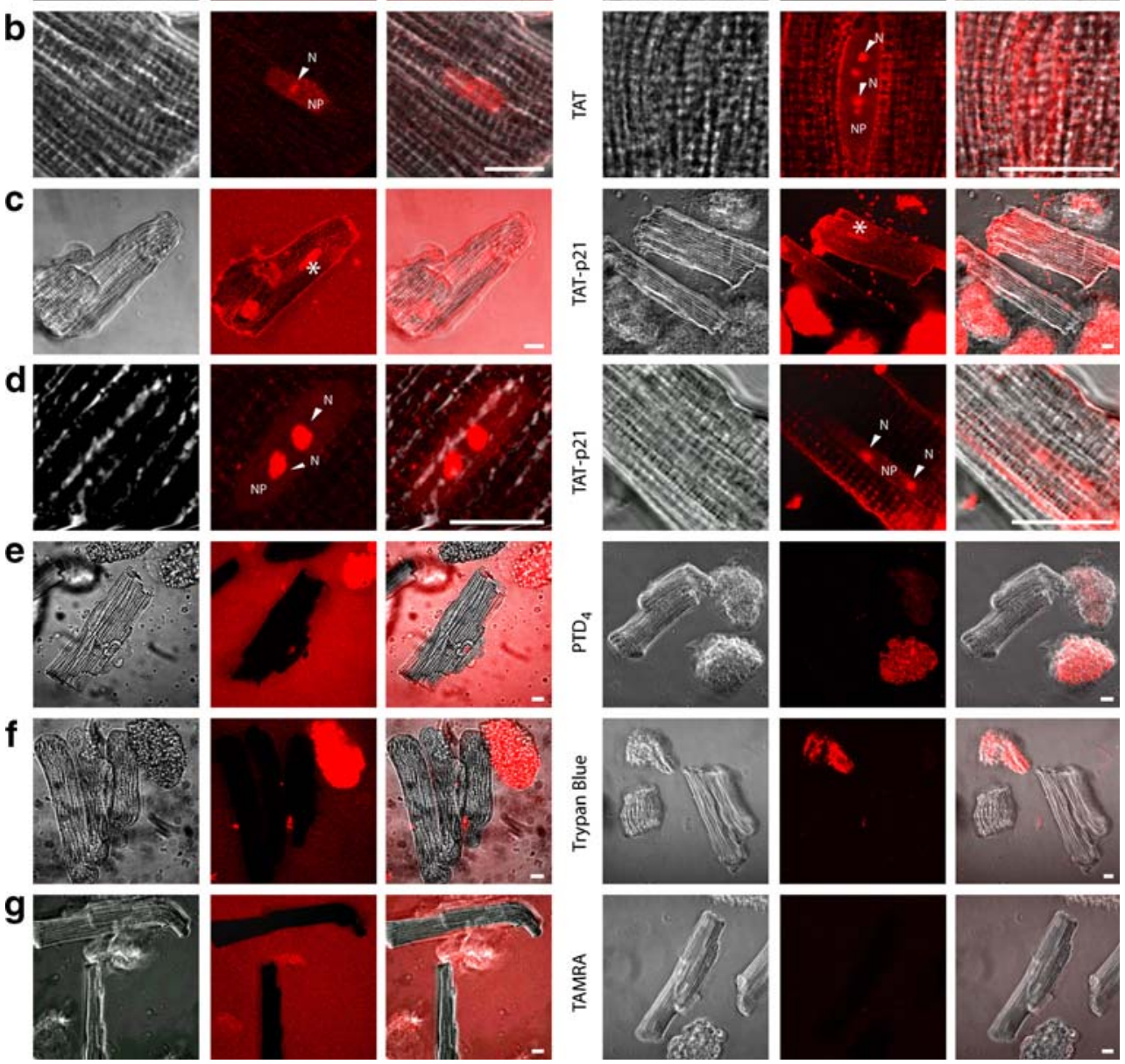

\section{定}
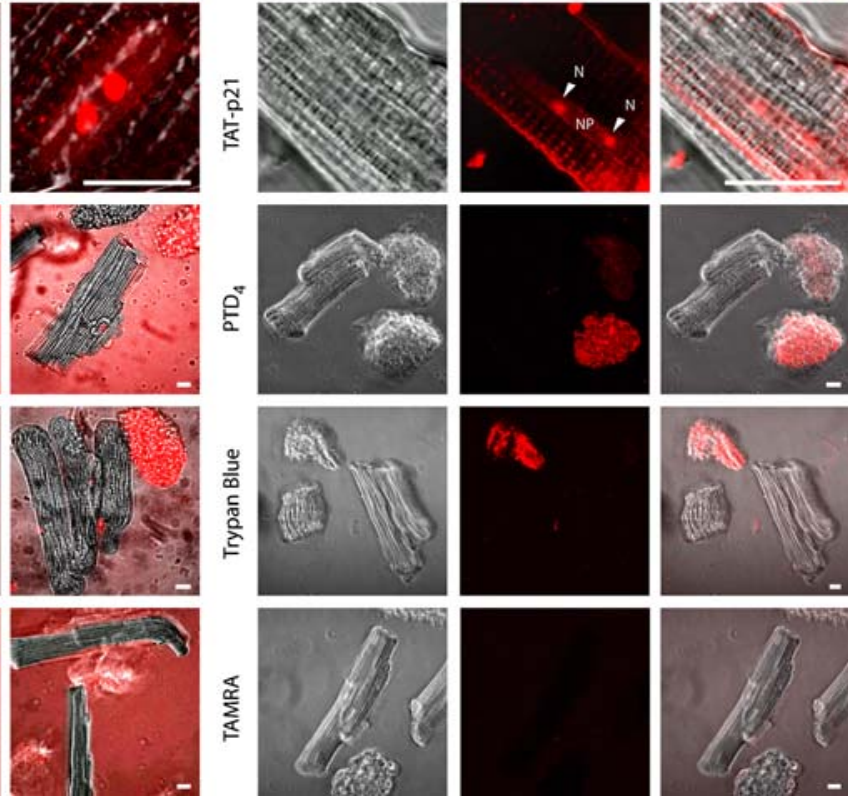

all settings, the main beam splitter was HFT UV/488/543/ 633 , and the specific parameters for the single fluorophores were: FITC, excited at $488 \mathrm{~nm}$ light, detected with a 500 530-nm bandpass filter; TAMRA or rhodamine excited at $543 \mathrm{~nm}$, detected with 565-615 bandpass filter; and trypan blue, excited with $633 \mathrm{~nm}$, detected with 650 longpass filter. Phase-contrast images were recorded with excitation at $488 \mathrm{~nm}$ and detection in the transmission channel. Laser power for observation was typically $1-5 \%$ (488 nm, $25 \mathrm{~mW})$ and $50-60 \%(543 \mathrm{~nm}, 1 \mathrm{~mW})$ unless otherwise indicated. Settings were adjusted in a way that image pixels were not over- or underexposed with the range indicator function in the Zeiss LSM image acquisition and examiner software version 3.2.

Measurement of cardiomyocyte shortening and $\mathrm{Ca}^{2+}$ transients Attached cardiomyocytes were washed with
HBSS. Cells were loaded with Fura-2-AM for $30 \mathrm{~min}$ at room temperature in the dark. The dye solution was removed, and cells were left on HBSS for another $15 \mathrm{~min}$. Only cardiomyocytes of optically intact rod-shaped morphology with clear cross-striation were analyzed. Cardiomyocytes were electrically stimulated until a stable steady-state contraction and Fura-2 signal could be monitored.

Cell shortening and Fura-2 signals were simultaneously measured at $30^{\circ} \mathrm{C}$ on an Ionoptix Contractility and Fluorescence System (Ionoptix). Cardiomyocytes were electrically stimulated with bipolar pulses of $5 \mathrm{~ms}$ duration at $1 \mathrm{~Hz}$. Cell shortening, expressed as percentage of resting cell length, was measured using the video-edge technique at a sampling rate of 240 per second. $\mathrm{Ca}^{2+}$ transients were monitored as ratio of fluorescence emission at $510 \mathrm{~nm}$ was obtained by alternate excitation at 340 and $380 \mathrm{~nm}$ (340/ 
380 ratio). Data files from 15 consecutive beats recorded at intervals were averaged for analysis. Subsequently, the cardiomyocytes were incubated with the peptides for 15 min without electrical stimulation. The peptide was then removed by replacing the peptide-containing HBSS buffer with normal HBSS buffer without the peptide. The cardiomyocytes were subsequently electrically stimulated, and both the shortening and Fura-2 signals were simultaneously recorded. The effect of the peptide on shortening amplitude and the Fura-2 signal was expressed in percent change compared to the steady-state signals obtained in the preincubation period.

\section{Results and discussion}

We recently demonstrated by live-cell confocal microscopy that the TAT CPP was able to shuttle fused peptides into primary blood cells and subsequently modulated their functional properties [10]. In this study, we tested whether TAT CPP could penetrate and if a peptide derived from the $\mathrm{N}$ terminus of VLC-1 fused to TAT is able to modulate the contractile function of primary adult cardiomyocytes.

Different basic peptides were incubated with freshly prepared cultures of cardiomyocytes, and peptide internalization was analyzed live by laser-scanning confocal microscopy. The fluorescently labeled minimal transduction domain TAT CPP of the transactivator of transcription from HIV-1 was readily taken up into cardiomyocytes and displayed a strong affinity to the nuclear compartment (Fig. 1a). It could also be visualized in a punctate pattern throughout the entire cardiomyocyte (Fig. 1a). To determine whether the TAT CPP is able to shuttle an attached peptide into cardiomyocytes, we used the TAMRA-labeled TAT$\mathrm{p} 21^{\mathrm{WAF} / \mathrm{CIP}}$ (TAT-p21) fusion peptide [33], which in addition to the transducing moiety contains 26 amino acids derived from the $\mathrm{C}$ terminus of human $\mathrm{p} 21^{\mathrm{WAF} / \mathrm{CIP}}$ protein. The uptake of this cargo peptide (assessed by appearance in nucleoli) occurred on a timescale of 5 to $10 \mathrm{~min}$ after peptide application. Its pattern of localization inside the cardiomyocytes was similar than that seen for TAT alone (Fig. 1c). Basic amino acid residues are a prerequisite for the transduction ability of CPPs [13, 25, 35], and peptides containing a minimum of six basic amino acids have been shown to traverse biological membranes [5, 18]. As a nontransducing control peptide, we chose the TAMRAlabeled peptide $\mathrm{PTD}_{4}$, which contains three arginines in total $[23,33]$. More than $1 \mathrm{~h}$ after application of this peptide to the cardiomyocyte culture, none of the healthy intact cardiomyocytes took up the fluorescent peptide (Fig. 1e). Similar results were obtained for the vital dye trypan blue (Fig. 1f) and the TAMRA fluorophore (Fig. 1g). Approximately $5 \%$ of cardiomyocytes in the cultures were dead or a

MAPKKPEPKDDAKAPAGRKKRRQRRR VLC-1 TAT

b
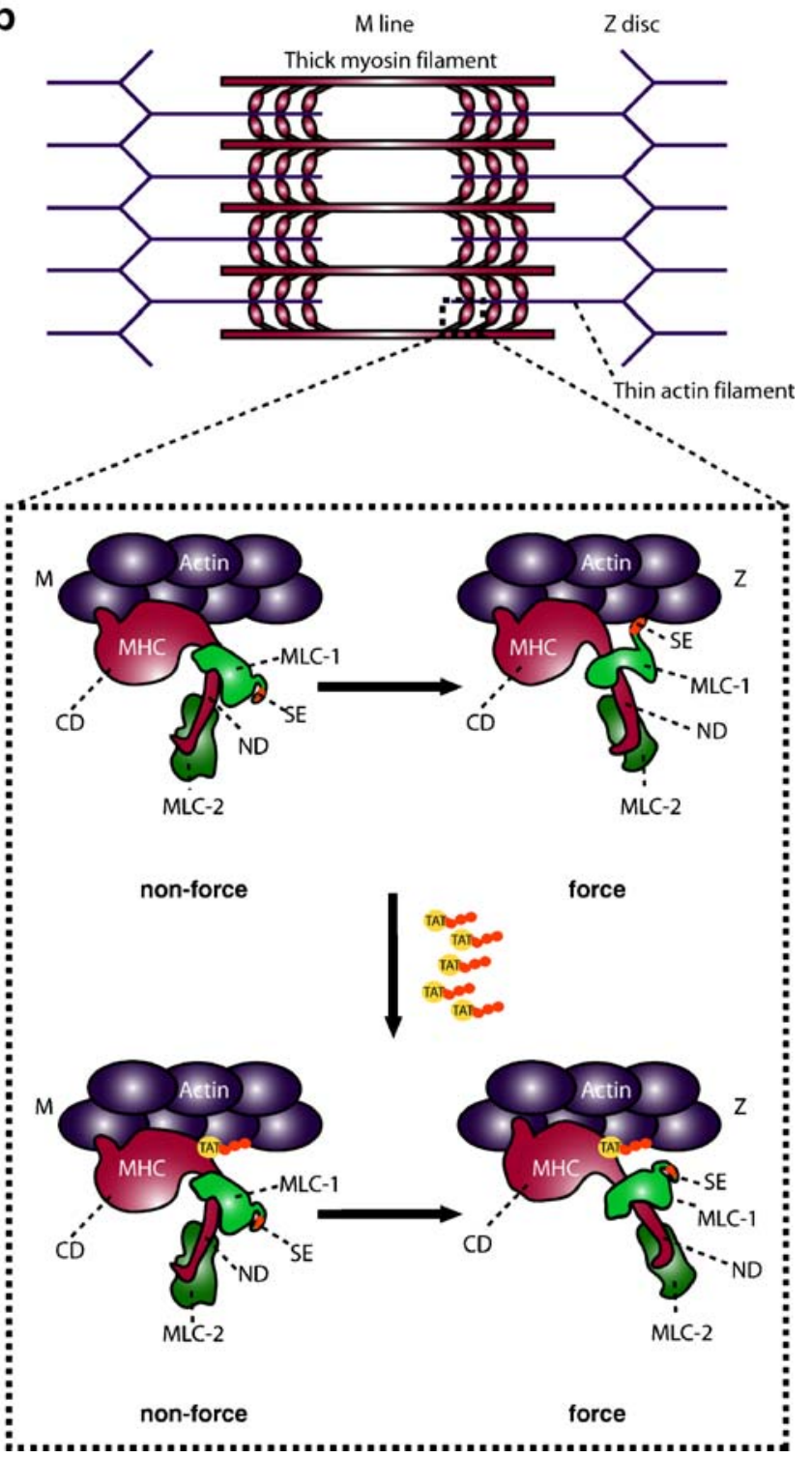

Fig. 2 Molecular hypothesis for the enhancement of cardiomyocyte contractility by the cell-permeable VLC-1 peptide. a Primary sequence of VLC-1-TAT peptide color-coded orange for the VLC-1and yellow for the TAT-moiety. b Schematic sliding filament model displaying actin in violet and the $\mathrm{MHC}$ in red. The higher magnification shows the catalytic domain $(C D)$ and the neck domain $(N D)$ of one molecule of the MHC. MLC proteins are colored green with the N-terminal SE inside the essential MLC-1 protein highlighted in red. Upon intramolecular conformational changes in the $\mathrm{CD}$ of MHC, the ND swings out, exposing the SE of MLC-1 to an actin molecule in direction to the Z-line. Treatment of cardiomyocytes with the transducible TAT peptide (yellow ball) fused to the SE-peptide (orange) blocks potential binding sites of the native MLC-1 N terminus. After the MHC rearrangement, the MLC-1 protein can no longer interact with actin and downregulate the myosin motor activity. The scheme is based on the pre- and postpower stroke model [19] developed with respect to crystallographic data on the Dicytostelium myosin motor domain $[15,32]$ 
harmed (visible in the phase-contrast images as not rod shaped and with no striations). These cells were flooded with both the CPPs as well as any other control dyes (Fig. 1c,e-g). The cell-permeable TAT-derived peptides displayed a similar enrichment in the nuclear compartment with strong accumulation inside nucleoli (arrowheads) as can be seen in the higher magnification images (Fig. 1b,d). This intranuclear distribution is basically determined by the TAT moiety, which includes a nuclear localization sequence [22, 29, 33].

Having shown that CPP TAT was able to shuttle fused peptides into living cardiomyocytes, we designed a transducible peptide comprising the actin-binding element of the ventricular isoform of human MLC-1 (VLC-1), i.e., the Nterminal residues 1-15 (VLC-1 peptide) connected to TAT, termed VLC-1-TAT (Fig. 2). The hearts of transgenic animals harboring minigenes encoding for the VLC-1 peptide revealed enhanced myosin motor activity and positive inotropic effects [21]. A possible molecular mechanism for the increase in myosin motor activity and contractility is illustrated in the scheme in Fig. 2. MLC-1 isoforms of vertebrate striated muscle play a regulatory role in myosin motor function: The N-terminal part of MLC-1 contains a sticky element (SE), which consists of several positively charged amino acids that bind to the $\mathrm{C}$ terminus of actin [3, 6, 16, 31]. The $46 \mathrm{~N}$-terminal amino acids of MLC-1 have previously been modeled on the basis of contemporary crystallographic data [2]. Interactions between the sticky MLC-1 element and actin serve as a negative modulator and decrease the activity of the myosin motor domain. Intracellular delivery of a synthetic sticky MLC-1 element by TAT-mediated transduction therefore would antagonize MLC-1/actin interaction. We predict this would increase myosin motor activity and enhance the shortening amplitude without change of the systolic free $\mathrm{Ca}^{2+}$ activation level of intact cardiomyocytes.

To first test whether the VLC-1 peptide itself might be taken up by isolated cardiomyocytes because of its basic charge, VLC-1 and VLC-1-TAT were applied for $15 \mathrm{~min}$ to freshly isolated cardiomyocytes under resting conditions or,

a

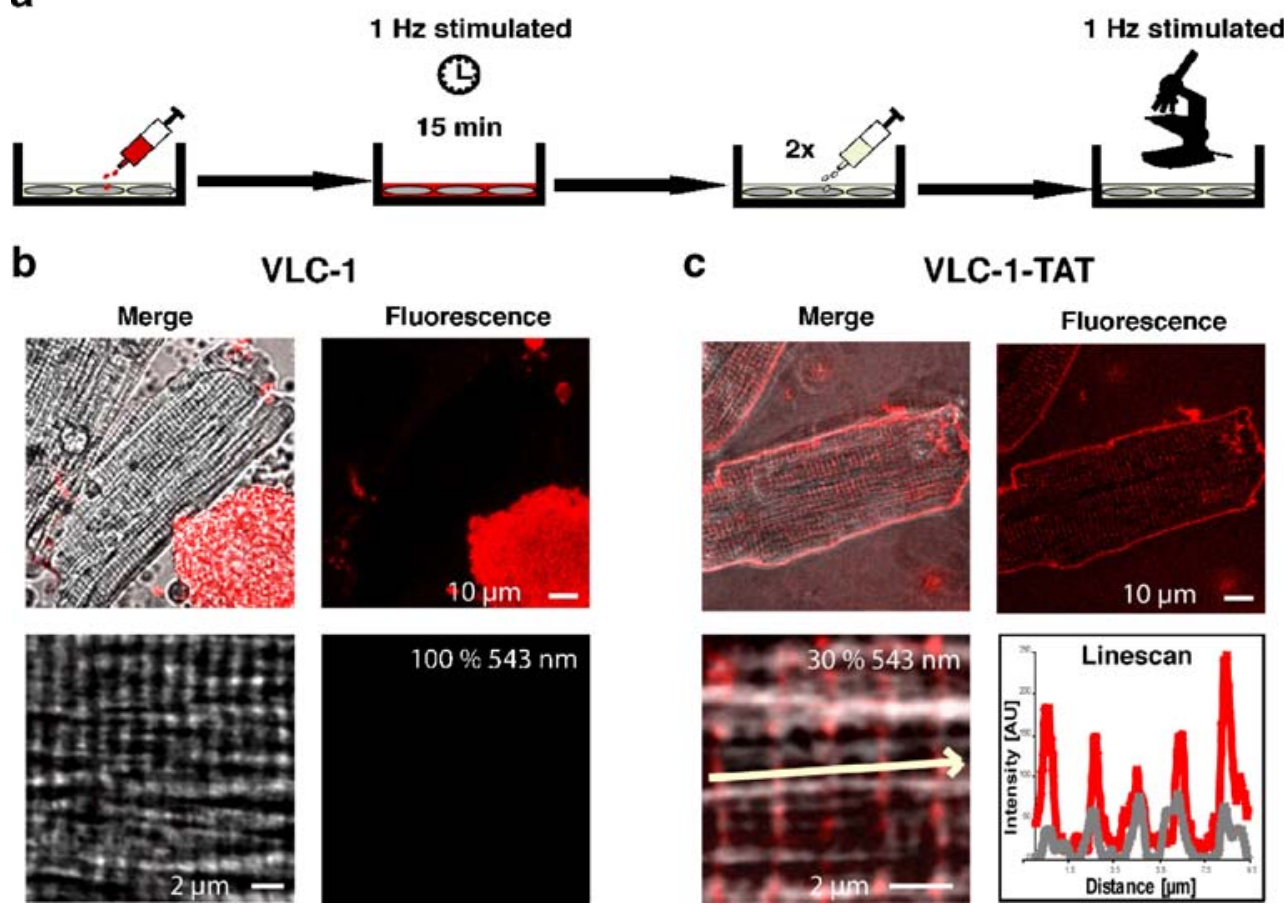

Fig. 3 Transduction and intracellular localization of VLC-1-TAT in isolated adult cardiomyocytes. a Scheme for the application of the VLC-1-derived peptides and confocal imaging. Peptides were applied at a concentration of $1 \mu \mathrm{M}$, incubated for $15 \mathrm{~min}$ to freshly isolated cardiomyocytes. After removal of the peptide solution, the cells were washed twice and kept in buffer or medium for direct live-cell confocal imaging microscopy. Subsequently, the transduced cardiomyocytes were electrically stimulated with $1 \mathrm{~Hz}$ for maximally $1 \mathrm{~h}$. b The negative control peptide TAMRA-labeled VLC-1 stained only dead cardiomyocytes (low magnification, upper panel) but failed to

get internalized into healthy cardiomyocytes even when $100 \%$ laser power was used to detect potentially weak signals (lower panel). c Application of TAT-VLC-1 to living cardiomyocytes led to rapid internalization of the peptide (upper panel). The lower panel shows transduced VLC-1-TAT at higher magnification in an overlay of the phase contrast and the TAMRA-fluorescence. The arrow indicates the direction of the intensity profile of gray and red intensities in the line scan for the localization analysis of VLC-1-TAT, which was present at sarcomeric structures with enrichment at the actin-containing I-bands (light bands in phase-contrast image) 
Fig. 4 Functional effects of cell permeable VLC-1-TAT in living adult cardiomyocytes. a Original registration of cell length (top) and cytosolic $\mathrm{Ca}^{2+}$ signals (Fura-2 signal, expressed as ratio $R$ between 340 and 380 excitation; bottom) of electrically paced adult rat cardiomyocytes before (basal) and after incubation with $1 \mu \mathrm{M}$ VLC1-TAT or $1 \mu \mathrm{M}$ TAT as control. b Statistical evaluation of the effects of different concentrations of transducible peptides $(0.5,1 \mu \mathrm{M})$ on fractional shortening ( $F S$; given in percent of basal contraction obtained before incubation with the peptide), maximal rate of FS $(+\mathrm{dFS} /$ $\left.\mathrm{d} t_{\max }\right)$, and maximal relaxation rate $\left(-\mathrm{dFS} / \mathrm{d} t_{\max }\right.$; both given in percent of basal values obtained before peptide incubation) of control peptide (TAT) and VLC1-TAT. c Statistical evaluation of the effects of different concentrations of transducible peptides $(0.5,1 \mu \mathrm{M})$ on peak Fura-2 fluorescence signal (expressed as ratio $R$ between 340 and 380 excitation, given in percent of basal R340/380 obtained before incubation with the peptide), maximal rate of R340/380 $\left(+\mathrm{dR} 340 / 380 / \mathrm{d} t_{\max }\right)$, and maximal rate of fluorescence decline $\left(-\mathrm{dR} 340 / 380 / \mathrm{d} t_{\max }\right.$; both given in percent of basal values obtained before peptide incubation) of control peptide (TAT) and VLC-1-TAT. Values are means \pm SEM, $n=6-9$ different cardiomyocytes at each peptide concentration used. Double asterisk, $p<0.01$; triple asterisk, $p<0.001$ ( $t$ test for paired values) a
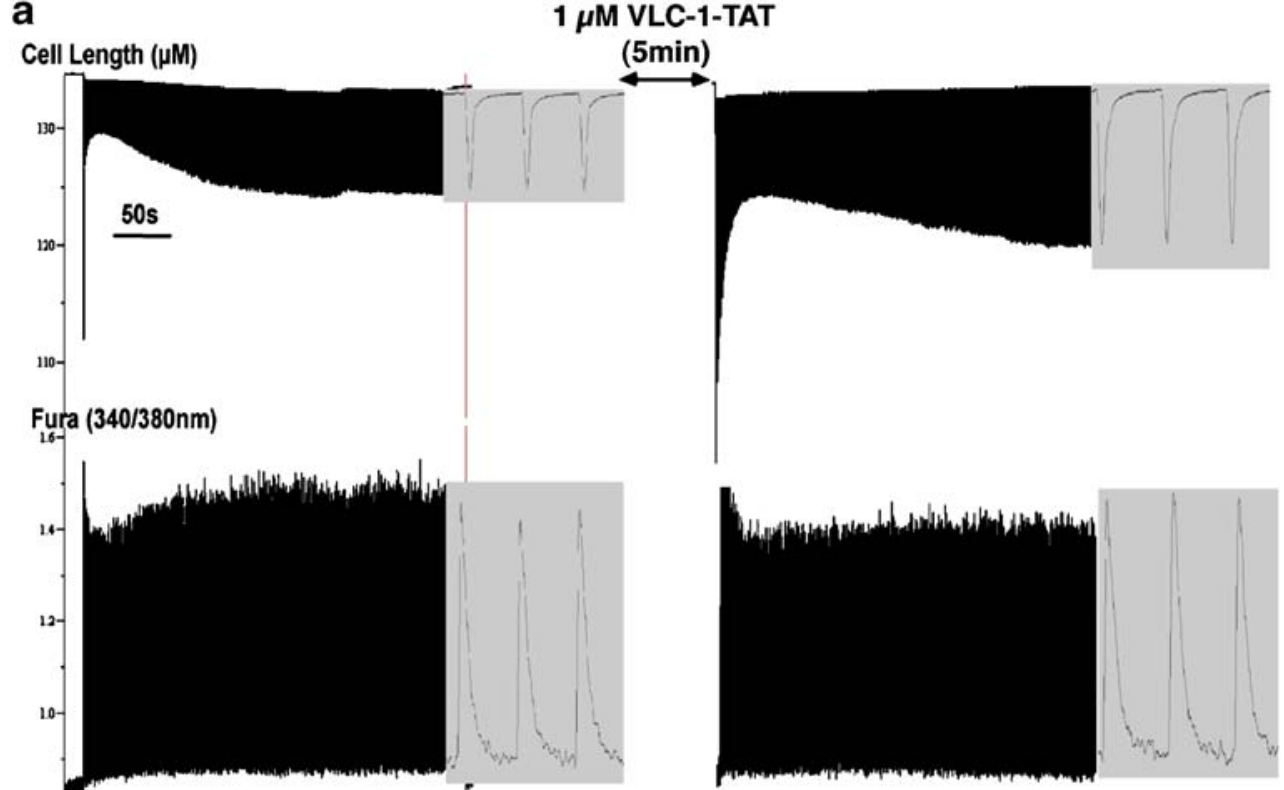

b

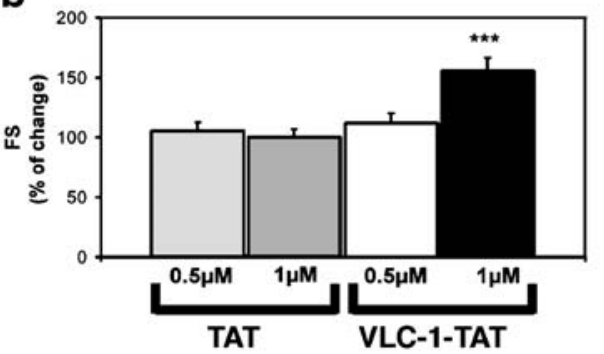

C
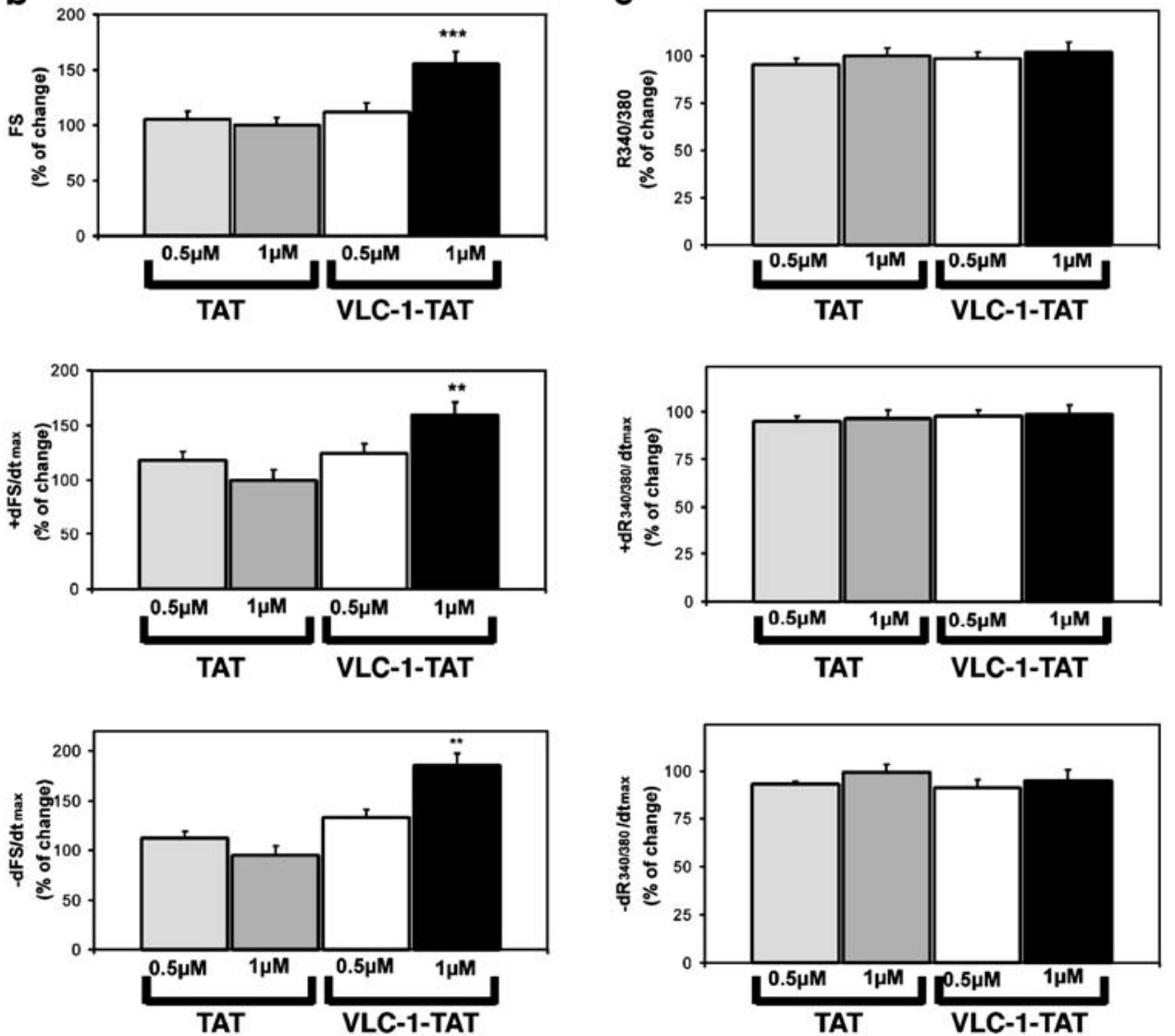

in another set of experiments, constant electric stimulation $(1 \mathrm{~Hz}, 20 \mathrm{~V})$. After the fluorescent peptides were washed away, the cells were analyzed live by confocal laserscanning microscopy (Fig. 3a). VLC-1 alone was not internalized into healthy cardiomyocytes and stained only compromised cells (upper panel, Fig. 3b). To ensure that low concentrations of intracellular VLC-1 were not missed, the laser intensity was increased to its maximum, and still no fluorescent signals were measured (lower panel, Fig. 3b). In contrast, VLC-1-TAT reached the intracellular 
compartments of more than $95 \%$ of adult cardiomyocytes (Fig. 3c).

Unlike the localization of the TAT and TAT-p21 peptides (Fig. 1), the VLC-1-TAT was not detected in the cell nucleus. Detailed analysis of the intracellular distribution of transduced VLC-1-TAT and correlation of the fluorescent signals with the phase contrast images (merge image, lower panel, Fig. 3c) demonstrated that the peptide associates with sarcomeric structures. It showed strong enrichment at the I-bands representing the nonoverlapping zones of the thin actin filaments with the thick myosin filaments (linescan, lower panel, Fig. 3c). After transduction, the VLC-1-TAT peptide remained inside the sarcomeric compartments of the cardiomyocytes for at least $1 \mathrm{~h}$ after transferring the loaded cardiomyocytes into the peptide-free buffer solution.

Using the same incubation protocol, we studied the effects of the cell-permeable VLC-1 peptide on muscle function by simultaneously monitoring the shortening amplitude and the systolic and diastolic cytoplasmic $\mathrm{Ca}^{2+}$ fluctuations (measured by Fura-2 fluorescence) of paced adult rat cardiomyocytes (Fig. 4a). As shown in Figs. 4b and $\mathrm{c}, 1 \mu \mathrm{M}$, but not $0.5 \mu \mathrm{M}$, of VLC-1-TAT significantly increased the shortening amplitude of adult cardiomyocyte, while the cytosolic $\mathrm{Ca}^{2+}$ signal remained unchanged. The same concentrations of control TAT peptide alone did not change the contractile state or the Fura-2 signals if compared to the basal state during the preincubation period. Higher concentrations of both control and test peptides induced deleterious effects on the cardiomyocyte contraction. It is interesting to note that not only the maximal amplitude of shortening rose but also the maximal rate of shortening and the maximal relaxation velocity increased significantly. Because the Fura-2 signal remained unchanged, the selective effect of the VLC-1-TAT peptide on the contraction parameters suggests a selective and direct effect on the function of the myosin cross-bridges. The $\mathrm{Ca}^{2+}$-sensitizing effect of the VLC-1-TAT peptide could be predicted from the mechanism of action, as the inhibition of the MLC-1/actin interaction may rise selectively myosin motor activity and therefore muscle contraction at a given activating free $\mathrm{Ca}^{2+}$ concentration, i.e., an inotropic effect without additional recruitment of $\mathrm{Ca}^{2+}$. It should be noted that the VLC-1-TAT peptide left the intracellular $\mathrm{Ca}^{2+}$-handling system unchanged, as seen by the fact that the kinetic parameters of the Fura-2 fluorescence signals remained normal (Fig. 4c).

In summary, we demonstrate by live-cell microscopy that CPPs and CPPs fused to peptides were taken up by adult cardiomyocytes with high efficiency and localize to their targets inside the cytoplasm and/or nucleus. The cellpermeable peptide VLC-1-TAT accumulated in the actincontaining I-band of the sarcomeres and was able to enhance the contractility of isolated adult cardiomyocytes without changing the myoplasmic $\mathrm{Ca}^{2+}$ levels. Importantly, the fact that VLC-1-TAT did not affect intracellular $\mathrm{Ca}^{2+}$ concentration and that it only has targets in striated muscle cells makes this peptide uniquely suited as a novel potential therapeutic tool to modulate heart function. VLC-1-TAT is a powerful new drug candidate to improve the contractile state of the failing heart.

Acknowledgments We thank W.-P. Schlegel and P. Pierschalek for technical assistance, R.M. Martin for invaluable help with confocal microscopy, and Jeff Stear for comments. G.T. was supported by the European Union (ESF Program). This work was funded in part by grants of the Deutsche Forschungsgemeinschaft and the Volkswagen Foundation to M.C.C and Deutsche Forschungsgemeinschaft to I.M.

\section{References}

1. Alvarez J, Hamplova J, Hohaus A, Morano I, Haase H, Vassort G (2004) Calcium current in rat cardiomyocytes is modulated by the carboxyl-terminal ahnak domain. J Biol Chem 279:1245612461

2. Aydt EM, Wolff G, Morano I (2007) Molecular modeling of the myosin-S1(A1) isoform. J Struct Biol. 159:158-163

3. Bottinelli R, Betto R, Schiaffino S, Reggiani C (1994) Unloaded shortening velocity and myosin heavy chain and alkali light chain isoform composition in rat skeletal muscle fibres. J Physiol 478(Pt 2):341-349

4. Brandman R, Disatnik MH, Churchill E, Mochly-Rosen D (2007) Peptides derived from the $\mathrm{C} 2$ domain of protein kinase $\mathrm{C}$ epsilon (epsilon PKC) modulate epsilon PKC activity and identify potential protein-protein interaction surfaces. J Biol Chem 282:4113-4123

5. Cardoso MC, Leonhardt H (2002) Protein transduction: a novel tool for tissue regeneration. Biol Chem 383:1593-1599

6. Chalovich JM, Stein LA, Greene LE, Eisenberg E (1984) Interaction of isozymes of myosin subfragment 1 with actin: effect of ionic strength and nucleotide. Biochemistry 23:48854889

7. Chen L, Hahn H, Wu G, Chen CH, Liron T, Schechtman D, Cavallaro G, Banci L, Guo Y, Bolli R, Dorn GW 2nd, MochlyRosen D (2001) Opposing cardioprotective actions and parallel hypertrophic effects of delta PKC and epsilon PKC. Proc Natl Acad Sci USA 98:11114-11119

8. Chen L, Wright LR, Chen CH, Oliver SF, Wender PA, MochlyRosen D (2001) Molecular transporters for peptides: delivery of a cardioprotective epsilonPKC agonist peptide into cells and intact ischemic heart using a transport system, R(7). Chem Biol 8:11231129

9. Chen M, Won DJ, Krajewski S, Gottlieb RA (2002) Calpain and mitochondria in ischemia/reperfusion injury. J Biol Chem 277:29181-29186

10. Choi M, Rolle S, Wellner M, Cardoso MC, Scheidereit C, Luft FC, Kettritz R (2003) Inhibition of NF-kappaB by a TAT-NEMObinding domain peptide accelerates constitutive apoptosis and abrogates LPS-delayed neutrophil apoptosis. Blood 102:2259-2267

11. Derossi D, Chassaing G, Prochiantz A (1998) Trojan peptides: the penetrating system for intracellular delivery. Trends Cell Biol 8:84-87

12. Dietz GP, Bahr M (2004) Delivery of bioactive molecules into the cell: the Trojan horse approach. Mol Cell Neurosci 27:85-131 
13. Dom G, Shaw-Jackson C, Matis C, Bouffioux O, Picard JJ, Prochiantz A, Mingeot-Leclercq MP, Brasseur R, Rezsohazy R (2003) Cellular uptake of Antennapedia Penetratin peptides is a two-step process in which phase transfer precedes a tryptophandependent translocation. Nucleic Acids Res 31:556-561

14. Fawell S, Seery J, Daikh Y, Moore C, Chen LL, Pepinsky B, Barsoum J (1994) Tat-mediated delivery of heterologous proteins into cells. Proc Natl Acad Sci USA 91:664-668

15. Fisher AJ, Smith CA, Thoden JB, Smith R, Sutoh K, Holden HM, Rayment I (1995) X-ray structures of the myosin motor domain of Dictyostelium discoideum complexed with MgADP.BeFx and MgADP.AlF4. Biochemistry 34:8960-8972

16. Fodor WL, Darras B, Seharaseyon J, Falkenthal S, Francke U, Vanin EF (1989) Human ventricular/slow twitch myosin alkali light chain gene characterization, sequence, and chromosomal location. J Biol Chem 264:2143-2149

17. Frankel AD, Pabo CO (1988) Cellular uptake of the tat protein from human immunodeficiency virus. Cell 55:1189-1193

18. Futaki S, Suzuki T, Ohashi W, Yagami T, Tanaka S, Ueda K, Sugiura Y (2001) Arginine-rich peptides. An abundant source of membrane-permeable peptides having potential as carriers for intracellular protein delivery. J Biol Chem 276:5836-5840

19. Geeves MA, Holmes KC (1999) Structural mechanism of muscle contraction. Annu Rev Biochem 68:687-728

20. Green M, Loewenstein PM (1988) Autonomous functional domains of chemically synthesized human immunodeficiency virus tat trans-activator protein. Cell 55:1179-1188

21. Haase H, Dobbernack G, Tunnemann G, Karczewski P, Cardoso C, Petzhold D, Schlegel WP, Lutter S, Pierschalek P, Behlke J, Morano I (2006) Minigenes encoding N-terminal domains of human cardiac myosin light chain-1 improve heart function of transgenic rats. FASEB J 20:865-873

22. Hauber J, Malim MH, Cullen BR (1989) Mutational analysis of the conserved basic domain of human immunodeficiency virus tat protein. J Virol 63:1181-1187

23. Ho A, Schwarze SR, Mermelstein SJ, Waksman G, Dowdy SF (2001) Synthetic protein transduction domains: enhanced transduction potential in vitro and in vivo. Cancer Res 61:474-477

24. Inagaki K, Hahn HS, Dorn GW 2nd, Mochly-Rosen D (2003) Additive protection of the ischemic heart ex vivo by combined treatment with delta-protein kinase $\mathrm{C}$ inhibitor and epsilon-protein kinase $\mathrm{C}$ activator. Circulation 108:869-875
25. Mai JC, Shen H, Watkins SC, Cheng T, Robbins PD (2002) Efficiency of protein transduction is cell type-dependent and is enhanced by dextran sulfate. J Biol Chem 277:30208-30218

26. Ono M, Sawa Y, Ryugo M, Alechine AN, Shimizu S, Sugioka R, Tsujimoto Y, Matsuda H (2005) BH4 peptide derivative from Bcl$\mathrm{xL}$ attenuates ischemia/reperfusion injury thorough anti-apoptotic mechanism in rat hearts. Eur J Cardiothorac Surg 27:117-121

27. Richard JP, Melikov K, Vives E, Ramos C, Verbeure B, Gait MJ, Chernomordik LV, Lebleu B (2003) Cell-penetrating peptides. A reevaluation of the mechanism of cellular uptake. J Biol Chem 278:585-590

28. Rohrbach S, Muller-Werdan U, Werdan K, Koch S, Gellerich NF, Holtz J (2005) Apoptosis-modulating interaction of the neuregulin/erbB pathway with anthracyclines in regulating Bcl-xS and Bcl-xL in cardiomyocytes. J Mol Cell Cardiol 38:485-493

29. Ruben S, Perkins A, Purcell R, Joung K, Sia R, Burghoff R, Haseltine WA, Rosen CA (1989) Structural and functional characterization of human immunodeficiency virus tat protein. $\mathrm{J}$ Virol 63:1-8

30. Ryser HJ, Hancock R (1965) Histones and basic polyamino acids stimulate the uptake of albumin by tumor cells in culture. Science 150:501-503

31. Seharaseyon J, Bober E, Hsieh CL, Fodor WL, Francke U, Arnold HH, Vanin EF (1990) Human embryonic/atrial myosin alkali light chain gene: characterization, sequence, and chromosomal location. Genomics 7:289-293

32. Smith CA, Rayment I (1996) X-ray structure of the magnesium (II).ADP.vanadate complex of the Dictyostelium discoideum myosin motor domain to 1.9 A resolution. Biochemistry $35: 5404-5417$

33. Tunnemann G, Martin RM, Haupt S, Patsch C, Edenhofer F, Cardoso MC (2006) Cargo-dependent mode of uptake and bioavailability of TAT-containing proteins and peptides in living cells. FASEB J 20:1775-1784

34. Zhang M, Kho AL, Anilkumar N, Chibber R, Pagano PJ, Shah AM, Cave AC (2006) Glycated proteins stimulate reactive oxygen species production in cardiac myocytes: involvement of Nox2 (gp91phox)-containing NADPH oxidase. Circulation 113:12351243

35. Ziegler A, Blatter XL, Seelig A, Seelig J (2003) Protein transduction domains of HIV-1 and SIV TAT interact with charged lipid vesicles. Binding mechanism and thermodynamic analysis. Biochemistry 42:9185-9194 